\title{
Prioritization of Factors that Determine Medical Practice Styles Using the Analytic Hierarchy Process
}

\author{
Sedat Bostan ${ }^{1}\left(\mathbb{0}\right.$, Gokhan Agac $^{2 *}$ (), Saime Sahinoz ${ }^{3}$ (i)
}

\begin{abstract}
${ }^{1}$ Department of Healthcare Management, Faculty of Health Sciences, Karadeniz Technical University, Trabzon, TURKEY
${ }^{2}$ Department of Healthcare Management, Faculty of Health Sciences, Sakarya University of Applied Sciences, Sakarya, TURKEY

${ }^{3}$ Department of Internal Medical Sciences, Faculty of Medicine, Ordu University, Ordu, TURKEY

*Corresponding Author: gokhanagacc@gmail.com
\end{abstract}

Citation: Bostan, S., Agac, G. and Sahinoz, S. Prioritization of Factors that Determine Medical Practice Styles Using the Analytic Hierarchy Process. European Journal of Environment and Public Health. 2022;6(1):em0100. https://doi.org/10.21601/ejeph/11558

\section{ARTICLE INFO}

Received: 2 Dec. 2021

Accepted: 26 Dec. 2021

\begin{abstract}
The medical profession has maintained its importance throughout human history. Communication between physician and patient is one of the most important issues that determine the success of the medical profession. In this success, physician behaviors and styles play a determining role in the practice of medicine. The aim of this study is to determine the factor weights affecting the practice styles in medicine and to prioritize them. The Analytic Hierarchy Process (AHP) is used in the study. The AHP technique is helpful for the decision maker as it prioritizes the factors based on their weights using a pairwise comparison matrix. The factor comparison data are obtained from a total of 22 clinician specialist physicians. According to the results of the application, the factors determining the practice style are Professional Experience (31.9\%), Medical Education (21.8\%), Patient and Disease (18.2\%), Personality (11.5\%), Institution (8.8\%), and Family and Social Environment (7.8\%), respectively. The concept of medical styles aimed to contribute to the development of the physicians' own styles and to create awareness. It is expected to contribute to medical education and professional development.
\end{abstract}

Keywords: medical practice styles, physicians’ behaviors, analytic hierarchy process

\section{INTRODUCTION}

The medical profession has been very important since the beginning of human history. When the history of medicine timeline is examined, it is seen that advances in medicine access to $2600 \mathrm{BC}$ and especially after the 19th century, has increased radically (Hajar, 2015). Therefore, with these developments, the importance of the medical profession has increased and its acceptance by the society has accelerated. Medical professionalism presents as a set of fundamental values, behaviors, and relationships that construct the public's trust (Wass, 2005). While medicine is seen by its members as a perfectionist profession that does not tolerate error, the physician is defined as a "ready for duty, honorable, honest and respectful" person (Musson, 2003; Straus and Straus, 2018). These definitions regarding medicine and physicians indicate that the profession is highly professionalized and universalized.
Like all people, physicians' education, experience, and personalities are shaped by their interaction with professional, cultural and physical environmental factors resulting in behavior and communication styles. Although each physician has his own professional approach, these forms of behavior are gathered around some basic behavioral and communication patterns. These forms of behavior and communication have traditionally been classified as paternalistic medicine, advisory medicine, and guiding medicine (Oguz, 1995; Ozlu, 2007).

Bostan (2017), with a different perspective, has reached a new classification system which he calls good practice medicine, conservative medicine, patient-friendly medicine and performance (quantitative) medicine style in a new field research. In the same study, in the formation of medical styles; medical education, professional experience, patient and disease, institution, personality, family and social environment were found to be effective and have been schematized.

This study is an extension version of the study titled "Hekimlik stillerine etkileyen faktörlerin analitik hiyerarşi süreci tekniğiyle ağırlıklarının hesaplanması [Calculating the weights of the factors affecting the styles of medicine with the analytical hierarchy process technique]" presented at the "3rd International and 13th National Congress on Health and Hospital Administration" held on the 10th-13th of October 2019 in Turkey. 
Medical education and professional experience are mostly emphasized in the formation a physician's behavior patterns and style. By combining teaching and clinical experience, medical students are expected to improve their communication skills throughout education. Interns' practice styles are related to patient communication and clinical performance (Fletcher et al., 2016).

It is stated that especially medical education provides basic behavioral patterns to the physician and improves it with professional experience. The physician is advised to adjust the style according to the patient's personality and disease (Kimball, 1982). The impact on personality, institution, family, and social environment have not been emphasized. However, Freidson (1984) emphasized that professional professions depend on the historical conditions and development of society.

In real life, the fact that patients are very satisfied with some physicians, and not with others, that they find some doctors successful and prefer them, and not other doctors, points out to the differences between physicians.

The physician's behavior and communication methods are the basic elements of professional functioning. Communication with physicians is an important part of the physician's visit and determines patients' satisfaction (Bertakis et al., 1998; Roter et al., 1987). Physicians differ in the way they interact and communicate with their patients, and there are also gender-related differences in physician communication (Roter et al., 2002).

Physicians consider the patient and the condition of the disease when performing their applications. Mast et al. (2007) demonstrated, as a result of their research, the necessity of adapting the physician's communication to the patients' specific needs or expectations. Physician-patient interaction and communication are particularly important in lifethreatening diseases such as cancer (Buckman and Kason, 1992).

Effective health care practitioners need to understand the biological, psychosocial and cultural factors of all patients (Gude et al., 2007). Successful patient-physician communication is crucial to identifying such factors and is associated with improving health outcomes (Hall, 2003; Taylor, 2009). In medical practice, patient-centered communication skills, with a tendency to understand patients' views, concerns, and feelings, have become an important element of the medical education curriculum (Brown, 2008; von Fragstein et al., 2008).

Akkas and Erdem (2017) argued that social, environmental and cultural factors are important in the emergence of diseases and that it is inevitable that the diseases, perception of the diseases and the medical intervention styles required by the diseases will change significantly according to the changes in the disease processes over time.

The research of Epstein and Nicholson (2009) on how gynecologists determine the treatment styles and how often they change, shows that changes in national clinical treatment guidelines and patient preferences have been proven to be crucial in shaping physicians' treatment.

This study aims to investigate and discusse the effects of medical education, professional experience, patient and
Table 1. The fundamental scale

\begin{tabular}{cc}
\hline Importance & Explanation (between $\boldsymbol{A}_{i}$ and $\boldsymbol{A}_{\boldsymbol{j}}$ alternatives) \\
\hline 1 & $A_{i}$ and $A_{j}$ have equal importance \\
\hline 3 & $A_{i}$ moderate important than $A_{j}$ \\
\hline 5 & $A_{i}$ strong important than $A_{j}$ \\
\hline 7 & $A_{i}$ very strong important than $A_{j}$ \\
\hline 9 & $A_{i}$ extreme importance than $A_{j}$ \\
\hline $2,4,6$, and 8 & Intermediate values \\
\hline
\end{tabular}

disease, institution, personality, family, and social environment, which affect the formation of the medical styles developed by physicians in their practice and communication with the patient. The study is the continuation of Bostan's (2017) previous study, which expresses the practice of physicians' professions and their behaviors towards patients with the concept of medical style.

\section{MATERIAL AND METHODS}

This study is carried out by obtaining expert opinion. The specialist physicians that participate in the study are selected from public hospitals, private hospitals, and a university hospital in Trabzon, which is a city in Northeast Turkey. These participants that filled out the pairwise comparison matrix are 22 clinician specialist physicians. Data are analyzed using Microsoft Excel program (Microsoft Corp., Redmond, Washington, USA).

The Analytical Hierarchy Process (AHP) is proposed by Saaty (1980). This technique compares the alternatives according to predetermined criteria. After the pairwise comparisons, the alternatives are ranked according to their weight. Thus, the decision maker can make the most appropriate decision based on the prioritized criteria. This study follows the steps of the AHP technique, as follows (Bhushan and Rai, 2004; Eisenhardt and Zbaracki, 1992; R. W. Saaty, 1987; Saaty, 1984, 2008):

Step 1: The problem is defined.

Step 2: The problem is transformed into a hierarchical formulation with several levels. The first level includes the goal of the decision; the intermediate levels are the criteria or sub-criteria to evaluate the alternative and the lowest level is a set of alternatives.

Step 3: The pairwise comparison matrices are constructed. Later, the relative importance of the particular element or alternative in the matrix is entered according to the fundamental scale (Table 1$)$. Let $a_{i j}=1 / a_{j i}(i, j=1,2,3, \ldots, n$ ), the pairwise comparison matrix $\left(A_{n \times n}=\left(a_{i j}\right)\right)$ is as follows:

$$
A=\begin{array}{cccccc}
C_{i} & A_{1} & A_{2} & A_{3} & \cdots & A_{n} \\
A_{1} & 1 & a_{12} & a_{13} & \cdots & a_{1 n} \\
A_{2} & a_{21} & 1 & a_{23} & \cdots & a_{2 n} \\
A_{3} & a_{31} & a_{31} & 1 & \cdots & a_{3 n} \\
\vdots & \vdots & \vdots & \vdots & \ddots & \vdots \\
A_{n} & a_{n 1} & a_{n 2} & a_{n 3} & \cdots & 1
\end{array}
$$

where $C_{i}(i=1,2,3, \ldots, n)$ and $A_{i}(\mathrm{i}=1,2,3, \ldots, n)$ represents criteria and element or alternative, respectively. 
Table 2. Random Index (RI)

\begin{tabular}{cccccccccccc}
\hline $\mathbf{n}$ & $\mathbf{1}$ & $\mathbf{2}$ & $\mathbf{3}$ & $\mathbf{4}$ & $\mathbf{5}$ & $\mathbf{6}$ & $\mathbf{7}$ & $\mathbf{8}$ & $\mathbf{9}$ & $\mathbf{1 0}$ & $\mathbf{1 1}$ \\
\hline RI & 0 & 0 & 0.58 & 0.9 & 1.12 & 1.24 & 1.32 & 1.41 & 1.45 & 1.49 & 1.51 \\
\hline
\end{tabular}

Table 3. Criteria and explanations used in the study

\begin{tabular}{|c|c|}
\hline Criteria & Explanation \\
\hline Personality & $\begin{array}{l}\text { The physicians'beliefs, habits, view on life, } \\
\text { philosophy of life, etc. }\end{array}$ \\
\hline $\begin{array}{c}\text { Medical } \\
\text { education }\end{array}$ & $\begin{array}{c}\text { Education at the medical faculty and specialty } \\
\text { training }\end{array}$ \\
\hline $\begin{array}{c}\text { Professional } \\
\text { experience }\end{array}$ & Experiences obtained from medical practices \\
\hline $\begin{array}{c}\text { Patient and } \\
\text { disease }\end{array}$ & $\begin{array}{l}\text { The patient'ssocio-economic level, beliefs, acute } \\
\text { or chronic illness, etc. }\end{array}$ \\
\hline $\begin{array}{l}\text { Family/social } \\
\text { environment }\end{array}$ & $\begin{array}{l}\text { Socio-economic level, beliefs, habits, social } \\
\text { acceptance, etc. of the family/social environment }\end{array}$ \\
\hline Institution & $\begin{array}{l}\text { Ownership of the institution (public-private) and } \\
\text { management style where the physician works }\end{array}$ \\
\hline
\end{tabular}

Step 4: The relative weights are obtained from the comparisons and the pairwise comparison matrix consistency is also checked. A way to obtain the relative weights is by dividing the elements in each column of the pairwise comparison matrix by the total sum of all the elements in their column and then averaging over the rows. On the other hand, the consistency of the comparison matrix of $n$ order is obtained by using the Equation (1) and Table 2. The value of the consistency ratio (CR) should be less than 0.1 (Saaty, 1984). If $A$ is an $n \times n$ comparison matrix, then w is weight vector for $\mathrm{A}$ and $\lambda_{\max }$ is the maximum eigen value of the comparison matrix. Thus,

$$
\mathrm{CR}=\mathrm{CI} / \mathrm{RI}
$$

where $\mathrm{CI}($ Consistency Index $)=\left(\lambda_{\max }-n\right) /(n-1)$ and $A w=$ $\lambda_{\max } w$.

\section{RESULTS AND DISCUSSION}

The problem of the study is to determine the factor weights affecting the practice styles and to prioritize them. The criteria used in the study are determined as factors affecting the practice styles recommended by Bostan (2017). The criteria are presented in Table 3. In addition, the hierarchical structure for the problem that identifies the factor that has the greatest effect on the practice styles is shown in Figure 1.

The normalized matrix and weights of the factors obtained because of the implementation are given in Table 4. According to Table 4, the consistency ratio of the obtained normalization decision matrix is valid $(0.017<0.1)$. In addition, the factors (and their weights) are Personality $\left(w_{1}=0.115\right)$, Medical Education $\left(w_{2}=0.218\right)$, Professional Experience $\left(w_{3}=0.319\right)$, Patient and Disease $\left(w_{4}=0.182\right)$, Family and Social Environment $\left(w_{5}=0.078\right)$, and Institution $\left(w_{6}=0.088\right)$. As a result, the factor weight affecting the practice styles is Professional Experience.

As a result, this study revealed that medical styles of physicians in health service delivery processes develop under the influence of experience, education, patient and disease status, family and social environment and personalities. At the same time, this research has shown that professional

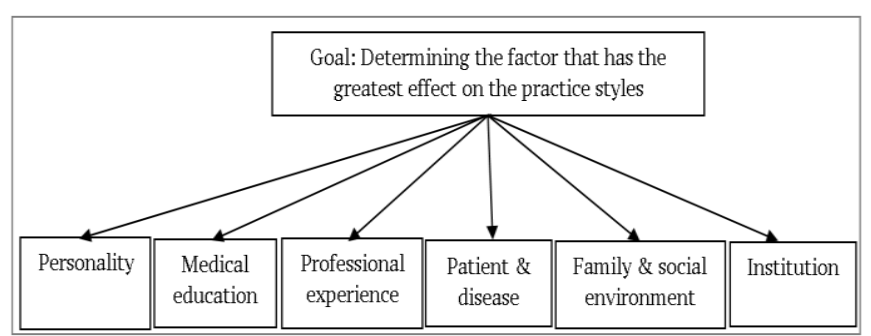

Figure 1. Hierarchical structure for the problem identifying the factors having the greatest effect on the practice styles

experience and medical education processes are more than $50 \%$ effective in improving the medical styles of physicians. Even if health system designers have difficulty in directing the patient and disease status, family and social environment and personality factors, they can be effective in the processes of medical education and professional experience of physicians.

Considering the relevant studies in the literature, Fletcher et al. (2016) stated that intern physicians combine medical teaching and clinical experience to communicate with patients. In this study, it is found that medical education had $21.8 \%$ and clinical experience $31.9 \%$ share in the formation of medical styles. Kimball (1982) emphasized that the physician should adjust the patient's approach to the patient's personality, Mast et al. (2007) argued that the physician should adapt the communication to the patient's specific needs or expectations, and Buckman and Kason (1992) stated that doctor-patient interaction is important in life-threatening diseases such as cancer. In the study, it is found that the effect of the patient and the disease on the physician styles is $18.2 \%$. Akkas and Erdem (2017) emphasized the impact of the social environment and the change in the social environment on the change in health. In this study, it is found that the effect of family and social environment on medical styles is $7.8 \%$.

The concept of medical styles is a concept introduced in literature by Bostan (2017). In this study, medicine styles were collected under the titles of Good Medicine Style, Conservative Medicine Style, Patient-Friendly Medicine Style, and Quantitative (performance oriented) Medicine Style. Medical education and health system policy makers can review medical education programs aimed at improving the professional styles of physicians, who are naturally the leaders, determinants, and directors of the health care process, to ensure more efficient and effective health services. For example, educational practices that can enable physicians to develop their behaviors within the framework of Good Medicine Style or Patient-Friendly Medicine Style can be added to medical education processes. In addition, the professional experience of physicians can be enriched with Good Medicine Style and Patient-Friendly Medicine Style practices.

\section{CONCLUSIONS}

In this study, it is determined that the most effective element in medical styles developed under the influence of medical education, professional experience, patient and disease, institution, personality, family, and social environment components is occupational experience with 
Table 4. Normalized decision matrix and factor weights

\begin{tabular}{cccccccc}
\hline & Personality & $\begin{array}{c}\text { Medical } \\
\text { education }\end{array}$ & $\begin{array}{c}\text { Professional } \\
\text { experience }\end{array}$ & Patient and disease & $\begin{array}{c}\text { Family and social } \\
\text { environment }\end{array}$ & $\begin{array}{c}\text { Institution } \\
\left.\text { Weight( } \boldsymbol{w}_{\boldsymbol{i}}\right)\end{array}$ \\
\hline Personality & 0.115 & 0.134 & 0.127 & 0.074 & 0.133 & 0.110 & 0.115 \\
\hline Medical education & 0.186 & 0.219 & 0.214 & 0.229 & 0.260 & 0.197 & 0.218 \\
\hline Professional experience & 0.295 & 0.333 & 0.326 & 0.414 & 0.210 & 0.335 & 0.319 \\
\hline Patient and disease & 0.243 & 0.150 & 0.124 & 0.157 & 0.215 & 0.202 & 0.182 \\
\hline $\begin{array}{c}\text { Family and social } \\
\text { environment }\end{array}$ & 0.070 & 0.068 & 0.125 & 0.059 & 0.081 & 0.069 & 0.078 \\
\hline Institution & 0.091 & 0.096 & 0.085 & 0.068 & 0.101 & 0.087 & 0.088 \\
\hline & & & & & & & $\mathbf{C R}=\mathbf{0 . 0 1 7}$ \\
\hline
\end{tabular}

31.9\% and the second element is medical education with $21.8 \%$. Moreover, it is found that the most important factor affecting the physician's attitudes and behaviors is patient and disease status with $18.2 \%$. It is understood that the personality factor has a significant effect with $11.5 \%$, the physician's institution affects the formation of medicine styles with $8.8 \%$ and the family and social environment with $7.8 \%$.

The concept of medical styles aimed to contribute to the development of the physicians' own styles and to create awareness. It is expected to contribute to medical education and professional development. At the same time, it is thought that the Ministry of Health and other institution owners, who are in the position of employers, will enrich the perspective of the medical profession. To develop the concept, new studies are needed on different samples from different perspectives. Ultimately, the study emphasized the importance of physician behavior patterns in health care delivery processes and gave an idea about the factors affecting physicians' medical styles and how physicians' medical styles could be improved in a positive way.

Author contributions: All co-authors have involved in all stages of this study while preparing the final version. They all agree with the results and conclusions.

Funding: No external funding is received for this article.

Declaration of interest: The authors declare that they have no competing interests.

Ethics approval and consent to participate: Not applicable.

Availability of data and materials: All data generated or analyzed during this study are available for sharing when appropriate request is directed to corresponding author.

\section{REFERENCES}

Akkas E. and Erdem R. (2017). An evaluation on determining the cases of medical professional culture. Suleyman Demirel University Visionary Journal, 8(17), 47-57. https://doi.org/10.21076/vizyoner.296310

Bertakis, K. D., Callahan, E. J., Helms, L. J., Azari, R., Robbins, J. A. and Miller J. (1998). Physician practice styles and patient outcomes: Differences between family practice and general internal medicine. Medical Care, 36(6), 879-891. https://doi.org/10.1097/00005650-199806000-00011

Bhushan, N. and Rai, K. (2004). Strategic decision making: Applying the analytic hierarchy process. Berlin/Heidelberg: Springer. https://doi.org/10.1007/b97668
Bostan, S. (2017). A research on the relationship between performance and medicine styles. Turkiye Klinikleri Journal of Health Sciences, 2(2), 92-99. https://doi.org/10.5336/ healthsci.2017-56269

Brown, J. (2008). How clinical communication has become a corepart of medical education in the UK. Medical Education, 42(3), 271-278. https://doi.org/10.1111/j.1365-2923.2007. 02955.x

Buckman, R. and Kason, Y. (1992). How to break bad news. A guide for health care professionals. Baltimore: Johns Hopkins University Press. https://doi.org/10.3138/ 9781487596989

Eisenhardt, K. M., Zbaracki, M. J. (1992). Strategic decision making. Strategic Management Journal, 13(S2), 17-37. https://doi.org/10.1002/smj.4250130904

Epstein, A. J. and Nicholson, S. (2009). The formation and evolution of physician treatment styles: An application to cesarean sections. Journal of Health Economics, 28(6), 11261140. https://doi.org/10.1016/j.jhealeco.2009.08.003

Fletcher, I., McCallum, R. and Peters, S. (2016). Attachment styles and clinical communication performance in trainee doctors. Patient Education and Counseling, 99(11), 18521857. https://doi.org/10.1016/j.pec.2016.05.019

Freidson, E. (1984). The changing nature of professional control. Annual Review of Sociology, 10(1), 1-20. https://doi.org/10.1146/annurev.so.10.080184.000245

Gude, T., Vaglum, P., Anvik, T., Baerheim, A., Eide, H., Fasmer, O. B., et al. (2007). Observed communication skills: How do they relate to the consultation content? A nation-wide study of graduate medical students seeing a standardized patient for a first-time consultation in a general practice setting. BMC Medical Education, 7(1), 43. https://doi.org/10.1186/1472-6920-7-43

Hajar, R. (2015). History of Medicine Timeline. Heart Views, 16(1), 43-45. https://doi.org/10.4103/1995-705X.153008

Hall, J. A. (2003). Some observations on provider-patient communication research. Patient Education and Counseling, 50(1), 9-12. https://doi.org/10.1016/S0738-3991(03)000727

Kimball, C. P. (1982). The biopsychosocial approach to the patient. Baltimore: Williams \& Wilkins.

Mast, M. S., Hall, J. A. and Roter, D. L. (2007). Disentangling physician sex and physician communication style: Their effects on patient satisfaction in a virtual medical visit. Patient Education and Counseling, 68(1), 16-22. https://doi.org/10.1016/j.pec.2007.03.020 
Musson, D. M. (2003). Personality determinants of professional culture: Evidence from astronauts, pilots and physicians $[\mathrm{PhD}$ thesis, The University of Texas at Austin].

Oguz, N. Y. (1995). Physician-patient relationship in clinical practice. Turkiye Klinikleri Journal of Medical Ethics-LawHistory, 3(2), 59-65.

Ozlu, T. (2007). In the context of mutual rights and responsibilities physician-patient relationship. Health Law Symposium Notes from A to Z, 20-28.

Roter, D. L., Hall, J. A. and Aoki, Y. (2002). Physician gender effects in medical communication. A meta-analytic Review. JAMA, 288(6), 756-764. https://doi.org/10.1001/ jama.288.6.756

Roter, D., Hall, J. A. and Katz, N. R. (1987). Relations between physicians' behaviors and simulated patients' satisfaction, recall, and impressions. Medical Care, 25(5), 437-451. https://doi.org/10.1097/00005650-198705000-00007

Saaty, R. W. (1987). The analytic hierarchy process-what it is and how it is used. Mathematical Modelling, 9(3-5), 161176. https://doi.org/10.1016/0270-0255(87)90473-8

Saaty, T. L. (1980) The analytic hierarchy process: Planning, priority setting, resource allocation. New York: McGraw-Hill.
Saaty, T. L. (1984). The analytic hierarchy process: Decision making in complex environments. In R. Avenhaus and R. K. Huber (Eds.), Quantitative assessment in arms control (pp. 285-308). Boston: Springer. https://doi.org/10.1007/978-14613-2805-6_12

Saaty, T. L. (2008). Decision making with the analytic hierarchy process. International Journal of Services Sciences, 1(1), 8398. https://doi.org/10.1504/IJSSCI.2008.017590

Straus, E. W. and Straus, A. (2018). Medical marvels: The 100 greatest advances in medicine. Buffalo: Prometheus Publishing.

Taylor, K. (2009). Paternalism, participation and partnership the evolution of patient centeredness in the consultation. Patient Education and Counseling, 74(2), 150-155. https://doi.org/10.1016/j.pec.2008.08.017

von Fragstein, M., Silverman, J., Cushing, A., Quilligan, S., Salisbury, H. and Wiskin, C. (2008). UK consensus statement on the content of communication curricula in undergraduate medical education. Medical Education, 42, 1100-1107. https://doi.org/10.1111/j.1365-2923.2008. 03137.x

Wass, V. (2005). Doctors in society. Medical professionalism in a changing world. Clinical Medicine Journal, 5(6 Suppl 1), 109-113. Available at: https://pubmed.ncbi.nlm.nih.gov/ 16408403/ 